\title{
Phase II study of CCI-779 in patients with recurrent glioblastoma multiforme
}

\author{
Susan M. Chang ${ }^{1}$, Patrick Wen ${ }^{2}$, Timothy Cloughesy ${ }^{3}$, Harry Greenberg ${ }^{4}$, David Schiff ${ }^{5}$, Charles \\ Conrad $^{6}$, Karen Fink ${ }^{7}$, H. Ian Robins ${ }^{8}$, Lisa De Angelis ${ }^{9}$, Jeffrey Raizer ${ }^{9}$, Kenneth Hess ${ }^{6}$, Ken \\ Aldape $^{6}$, Kathleen R. Lamborn ${ }^{1}$, John Kuhn ${ }^{10}$, Janet Dancey ${ }^{11}$, Michael D. Prados ${ }^{1}$ for the North \\ American Brain Tumor Consortium and the National Cancer Institute \\ ${ }^{1}$ University of California, San Francisco; ${ }^{2}$ Dana Farber Cancer Institute; ${ }^{3}$ University of California, Los Angeles; \\ ${ }^{4}$ University of Michigan; ${ }^{5}$ University of Virginia; ${ }^{6} \mathrm{MD}$ Anderson Cancer Center; ${ }^{7}$ University of Texas, Southwestern; \\ ${ }^{8}$ Unversity of Wisconsin; ${ }^{9}$ Memorial Sloan Kettering Cancer Center; ${ }^{10}$ University of Texas, San Antonio; ${ }^{11}$ Cancer \\ Therapy Evaluation Program, National Cancer Institute
}

Key words: chemotherapy, CCI-779, rapamycin, glioblastoma multiforme, recurrent, efficacy

\begin{abstract}
Summary
Purpose: Loss of PTEN, which is common in glioblastoma multiforme (GBM), results in activation of the mammalian target of rapapmycin (mTOR), thereby increasing mRNA translation of a number of key proteins required for cell-cycle progression. CCI-779 is an inhibitor of mTOR. The primary objectives of this study were to determine the efficacy of CCI-779 in patients with recurrent GBM and to further assess the toxicity of the drug. Experimental Design: CCI-779 was administered weekly at a dose of $250 \mathrm{mg}$ intravenously for patients on enzyme-inducing anti-epileptic drugs (EIAEDs). Patients not on EIAEDs were initially treated at $250 \mathrm{mg}$; however, the dose was reduced to $170 \mathrm{mg}$ because of intolerable side effects. Treatment was continued until unacceptable toxicity, tumor progression, or patient withdrawal. The primary endpoint was 6-month progression-free survival. Results: Forty-three patients were enrolled; 29 were not on EIAEDs. The expected toxicity profile of increased lipids, lymphopenia, and stomatitis was seen. There were no grade IV hematological toxicities and no toxic deaths. One patient was progression free at 6 months. Of the patients assessable for response, there were 2 partial responses and 20 with stabilization of disease. The median time to progression was 9 weeks. Conclusions: CCI-779 was well tolerated at this dose schedule; however, there was no evidence of efficacy in patients with recurrent GBM. Despite initial disease stabilization in approximately $50 \%$ of patients, the durability of response was short. Because of the low toxicity profile, CCI-779 may merit exploration in combination with other modalities.
\end{abstract}

\section{Introduction}

Novel therapeutic strategies are needed for the treatment of patients with recurrent glioblastoma multiforme $(\mathrm{GBM})$, for whom the median survival is currently 4 to 6 months. Recent advances in the understanding of aberrant molecular and cytogenetic pathways involved in GBM pathogenesis and progression have led to the rational targeting of some of these pathways. A significant percentage of GBM have altered PTEN gene suppression activity [1], which results in the increased activity of the phosphotidylinositol 3-kinase (PI3K)/Akt pathway. The PI3K/Akt pathway activates the mammalian target of rapamycin (mTOR), increasing translation of a number of key proteins required for cell-cycle progression. The presence of PTEN gene alterations and the subsequent activation of these downstream pathways have been associated with poor prognosis in anaplastic astrocytoma, anaplastic oligodendroglioma, and GBM [2-4]. Restoration of PTEN function or targeting of the components of the PI3K/Akt/mTOR pathways can result in cell-cycle arrest, apoptosis, or reduced tumorigenicity and are rational targets for clinical evaluation.

CCI-779 is a dihydroxymethyl propionic acid ester of the immunosuppressive agent sirolimus (rapamycin, Rapamune $^{\circledR}$ ) that targets the mTOR pathway. CCI-779 binds to FKBP-12 to form a complex that interacts with mTOR, which results in cell-cycle arrest by means of inhibition of RNA translation [5-7]. CCI-779 is lipid soluble and inhibits the growth of a number of human tumor lines in nude mouse models, including GBM [8]. Based on these promising pre-clinical studies, there was an interest 
in evaluating this novel agent in patients with recurrent GBM.

There is increasing evidence that brain tumor patients receiving $\mathrm{P} 450$ enzyme-inducing anti-epileptic drugs (EIAEDs) have markedly altered pharmacokinetics, resulting in accelerated drug metabolism. CCI-779 and rapamycin are substrates for the cytochrome $\mathrm{P} 450$ isoenzyme 3A4. A North American Brain Tumor Consortium phase I study established the maximum tolerated dose of CCI-779 in patients with malignant glioma who are taking EIAEDs at $250 \mathrm{mg}$ [9].

We report on the results of a phase II study of CCI-779 in patients with recurrent GBM. The primary objectives of this study were to determine the efficacy (defined by 6-month progression-free survival) of patients with recurrent GBM treated with CCI-779 and to further assess its toxicity.

\section{Methods}

\section{Patient eligibility}

Patients at least 18 years of age were eligible for participation if they had histopathologically confirmed GBM with recurrence documented by neuroimaging. Patients were also eligible if they had a prior low-grade glioma and a subsequent histological confirmation of GBM. Patients must have relapsed after prior treatment with radiation therapy, with an interval of at least 4 weeks from treatment with radiation therapy, and could not have undergone treatment for more than 2 prior relapses. Patients were required to have a Karnofsky Performance Scale (KPS) score of at least 60, an estimated survival of $>8$ weeks, hematologic, renal, and hepatic status within the normal ranges, levels of cholesterol $<350 \mathrm{mg} / \mathrm{dl}$, and levels of triglyceride $<400 \mathrm{mg} / \mathrm{dl}$. No exclusions were made based on gender, race, minority status, or economic status. Female patients were not pregnant or nursing, and all patients (both men and women) agreed to practice birth control during and for 3 months after completing the study. Patients or their surrogates signed an institutionally approved Committee on Human Research consent form. Patients did not have any serious intercurrent illness or disease that obscured or altered drug metabolism.

\section{Study design}

Patients were treated with CCI-779 as a 30-minute intravenous (IV) infusion weekly with no rest period required. For the purpose of evaluation, a cycle was defined as every 4 weeks. Because of the documented side effect of lipid elevation, allowance for the use of lipid-lowering agents was incorporated into the phase II study. After every 2 cycles of treatment, patients underwent re-staging with neuro-imaging and clinical evaluation including neurological examination and assessment of corticosteroid use. Determination of tumor status was made using standard criteria [10]. Therapy with CCI-779 was continued as long as the tumor was stable or smaller in size and the patient was clinically stable or improved on stable or decreasing corticosteroid doses. Treatment continued indefinitely as long as there were no unacceptable toxicities, patient refusal to continue participation, or tumor progression. For all patients, the initial phase II dose was $250 \mathrm{mg}$ IV weekly. Toxicities were graded according to the NCI Common Toxicity Criteria (CTC Version 2.0) scale.

\section{Statistical considerations}

Enrollment of 32 patients would give a $92 \%$ probability of successfully detecting a 35\% 6-month progression free-survival (PFS) rate and a $90 \%$ probability of rejecting the drug if the 6-month progression-free survival (PFS) rate was $15 \%$ or less. The study would be considered worth pursuing if at least $8 / 32$ patients had 6-month progression-free survival.

\section{Results}

Forty-three patients were enrolled (65\% male). All patients enrolled had primary GBM. The median age was 48 years (range 26-71 years) and the median KPS was 90. Patients' characteristics are shown in Table 1. For patients not on EIAEDS, the initial dose was $250 \mathrm{mg}$ weekly; however, this was reduced to $170 \mathrm{mg}$ weekly in many patients because of intolerable side effects (stomatitis). Thirteen patients were treated at $250 \mathrm{mg}$ and 16 patients at $170 \mathrm{mg}$. The 14 patients on EIAEDs were treated at $250 \mathrm{mg}$. The major toxicities observed were elevation in lipid profiles, lymphopenia, and stomatitis (Table 2). Twenty-one patients were started on lipid-lowering agents during the study; none were on lipid-lowering agents at the time of enrollment. There were no grade IV hematological toxicities and no toxic deaths.

Two patients were lost to follow-up and were censored for the endpoint of progression-free survival. Of the 41 evaluable patients, only 1 patient was progression free at 6 months. There were 2 partial responses and 20 patients who had stabilization of disease; however, the median time to progression was short, at 9 weeks. The Kaplan Meier estimate for time to progression is shown in Figure 1.

\section{Discussion}

Mutations of the PTEN gene result in constitutive activation of the PI3K pathway, resulting in increased 
Table 1. Patients' characteristics

\begin{tabular}{cll}
\hline & $\begin{array}{l}\text { Patients taking } \\
\text { NEIAEDs }(N=29)\end{array}$ & $\begin{array}{l}\text { Patients taking } \\
\text { EIAEDs }(N=14)\end{array}$ \\
\hline $\begin{array}{c}\text { Median Age in } \\
\text { years (range) }\end{array}$ & $51(29-71)$ & $46(26-71)$ \\
$\begin{array}{c}\text { Karnofsky } \\
\text { Performance Status } \\
90-100\end{array}$ & & \\
$\leq 80$ & $13(44.8 \%)$ & $4(28.6 \%)$ \\
Sex $\begin{array}{l}\text { Female } \\
\text { Male }\end{array}$ & $16(55.2 \%)$ & $10(71.4 \%)$ \\
Race & $10(34.5 \%)$ & $5(35.7 \%)$ \\
Black & $19(65.5 \%)$ & $9(64.3 \%)$ \\
$\quad$ White & $2(6.9 \%)$ & $0(0 \%)$ \\
Prior Chemotherapy & $27(93.1 \%)$ & $14(100 \%)$ \\
Regimens & & \\
0 & $2(6.9 \%)$ & $0(0 \%)$ \\
1 & $22(75.9 \%)$ & $9(64.3 \%)$ \\
2 & $2(6.9 \%)$ & $5(35.7 \%)$ \\
3 & $3(10.3 \%)$ & $0(0 \%)$ \\
\hline
\end{tabular}

Table 2. Grade III and IV toxicities observed $(n=43$ patients) using the National Cancer Institute common toxicity grading system

\begin{tabular}{lrl}
\hline Toxicity & Grade III $(\%)$ & Grade IV (\%) \\
\hline Lymphopenia & 14 & - \\
Anemia & 5 & - \\
Stomatitis & 2 & 2 \\
Elevated cholesterol & 9 & 7 \\
Elevated triglyceride & 5 & 5 \\
\hline
\end{tabular}

proliferation, dysregulation of the cell cycle, and resistance to chemotherapy-induced apoptosis. This is relevant in glioma therapy, as PTEN mutations are present in approximately $40 \%$ to $60 \%$ of all GBM, and alterations in PTEN are of prognostic significance [1]. One of the downstream pathways of PTEN involves mTOR, which is inhibited by CCI-779. Based on preclinical data on CCI779 , which showed potential antiglioma activity, we evaluated this agent in patients with recurrent GBM. Because CCI-779 and rapamycin are metabolized by the p 450 hepatic enzyme system, and concurrent use of EIAEDs may result in increased clearance of CCI-779, the appropriate phase II dose in patients on enzyme-inducing antiepileptic agents was established first [9]. The agent was well tolerated, with side effects as described at a similar dosing schedule in solid cancers [11].

This phase II study sought to evaluate the efficacy of CCI-779 as defined by 6-month progression-free survival in patients with recurrent GBM irrespective of the use of EIAEDs. Unfortunately, despite good tolerance of the agent, CCI-779 did not demonstrate sufficient antitumor activity to warrant further study as a single agent. There are possibly several reasons for this lack of efficacy. Although the pharmacokinetic results suggested adequate systemic concentrations of the drug to block mTOR [9], actual drug concentration within the tumors had not been documented. The presence of the blood-brain barrier and inadequate penetration of the agent to the infiltrative tumor cells may be a barrier for drug delivery. This emphasizes the challenges of performing clinical trials of novel agents in patients with malignant glioma [12]. A small pilot study being performed by the North American Brain Tumor Consortium involves 10 patients who will be administered CCI-779 prior to planned surgical resection of a recurrent malignant glioma. In addition to evaluation of inhibition of mTOR, measurements of tumor drug levels are planned and may help in answering this question.

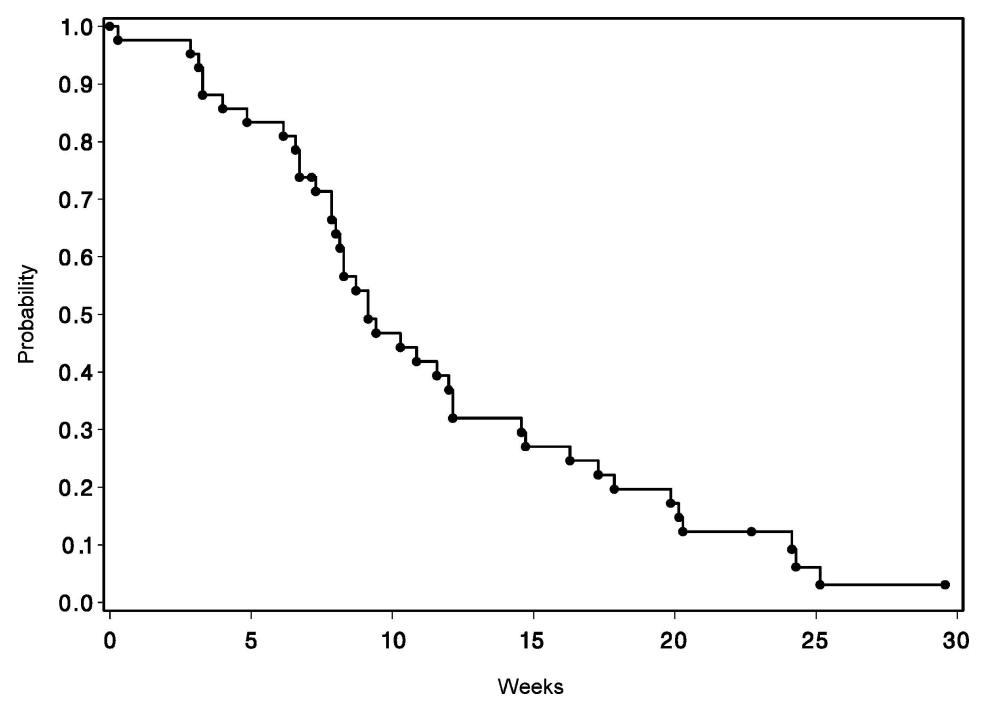

Figure 1. Kaplan Meier estimate for time to progression for 41 patients with recurrent GBM treated with CCI-779. 
PTEN status of the tumors at the time of enrollment was not required or mandated. As with any 'targeted' therapy, enrollment of patients lacking the specific genetic abnormality may cause underestimation of the true efficacy of the agent. This poses a significant challenge in the selection of patients, given the invasive nature of tissue acquisition. Retrospective analysis of tissue samples is also fraught with potential for misinterpretation, as the specimens analyzed tend to be representative of the tumor at the time of initial diagnosis and not at the time of recurrence following therapy with radiation and/or chemotherapy. Changes in the molecular targets could theoretically occur with time, and the most informative sample would be at the time of treatment with the targeted agent.

It is well accepted that many cell-signaling pathways overlap, and there may actually be an interdependence of activity within these pathways. Targeting only one aspect of a pathway may be successful in proof-of-principle studies; however, this may unfortunately not translate into a benefit of clinical significance for the patient. An example of this is the recent demonstration of the alterations in cyclin D1/c-myc expression as critical determinants of cell sensitivity to mTOR inhibitors, which suggested that excessive transcription of these genes in tumors may inhibit the effectiveness of mTOR inhibitors [13]. Other relationships between signaling molecules have been demonstrated in vivo by Choe et al., using human GBM tissue microarrays [14]. In addition to the well-accepted relationship of the PTEN and PI3K pathways, the authors show correlation of PTEN with the family of forkhead transcription factors as well as the mutant epidermal growth factor receptor vIII. Others have also described the relationship of epidermal growth factor receptor (EGFR) with this particular signaling pathway [15]. This is particularly relevant for GBM, as frequent mutation of EGFR is seen and is known to confer an unfavorable prognosis [16]. There may be a scientific rationale for the combination of EGFR inhibitors with mTOR inhibitors given these findings. These studies also suggest that the signaling abnormalities specific to the individual patient may be important information for stratification into clinical trials of these targeted agents.

In addition to these reasons for the limited efficacy of CCI-779 observed in this study, potential mechanisms of resistance to rapamycin and its analogs include mutation of the binding proteins FKBP-12, alteration of the downstream effectors of mTOR, and mutation of mTOR itself $[17,18]$. Many of these mechanisms are being elucidated, but their clinical significance needs to be further studied.

It is anticipated that many of these cytostatic agents that target specific signaling pathways are unlikely to have durable control of tumor growth as single agents because of the reasons described above. There is the danger of discarding a potentially useful agent that could be used in combined modality therapy because of its lack of efficacy as a single agent. Preclinical data support the use of mTOR inhibitors in combination with radiation and chemotherapy [19-21]. The current paradigm of evaluating the efficacy of these drugs as single agents first rather than in combination with radiation therapy, chemotherapy, or other targeted therapies may inherently delay appropriate use of these novel compounds. Given that the agent is well tolerated, proceeding with the study of these combinations may be worthy of further study.

\section{Conclusions}

This phase II study of CCI-779 in patients with recurrent GBM on and off enzyme-inducing anti-epileptic drugs failed to demonstrate any efficacy as a single agent. Because CCI-779 was well tolerated, further combination strategies may merit evaluation.

\section{Acknowledgments}

\begin{tabular}{|c|c|c|}
\hline Institution & $\begin{array}{l}\text { Member/Affiliate } \\
\text { Grant Number }\end{array}$ & $\begin{array}{l}\text { GCRC Grant } \\
\text { Number }\end{array}$ \\
\hline $\begin{array}{l}\text { University of California, } \\
\text { San Francisco }\end{array}$ & $\begin{array}{l}\text { NABTC \# CA62399 } \\
\text { Member \#CA62422 }\end{array}$ & M01-RR00079 \\
\hline $\begin{array}{l}\text { University of Texas, M.D. } \\
\text { Anderson Cancer Center }\end{array}$ & CA62412 & CA16672 \\
\hline $\begin{array}{l}\text { Dana Farber Cancer } \\
\text { Center }\end{array}$ & U01CA62407-08 & N/A \\
\hline $\begin{array}{l}\text { University of Texas, } \\
\text { Southwestern } \\
\text { Medical Center }\end{array}$ & CA62455-08 & M01-RR00633 \\
\hline $\begin{array}{l}\text { University of Texas, } \\
\text { San Antonio }\end{array}$ & CA62426 & N/A \\
\hline $\begin{array}{l}\text { University of California, } \\
\text { Los Angeles }\end{array}$ & $\begin{array}{l}\text { U01 CA62399 } \\
\quad \# 022330 \text { for } \\
\text { NABTC98-03 only }\end{array}$ & M01-RR0865 \\
\hline University of Michigan & U01CA62399 & M01-RR00042 \\
\hline $\begin{array}{l}\text { Memorial Sloan-Kettering } \\
\text { Cancer Center }\end{array}$ & 5-U01CA62399-09 & \\
\hline $\begin{array}{l}\text { University of Wisconsin } \\
\text { Hospital }\end{array}$ & U01CA62421-08 & M01 RR03186 \\
\hline
\end{tabular}

The authors thank Sharon Reynolds, Department of Neurological Surgery, University of California, San Francisco for editorial support.

\section{References}

1. Knobbe CB, Merlo A, Reifenberger G: Pten signaling in gliomas. Neuro-oncol 4: 196-211, 2002

2. Sasaki H, Zlatescu MC, Betensky RA, Ino Y, Cairncross JG, Louis DN: PTEN is a target of chromosome 10q loss in anaplastic 
oligodendrogliomas and PTEN alterations are associated with poor prognosis. Am J Pathol 159: 359-367, 2001

3. Sano T, Lin H, Chen X, Langford LA, Koul D, Bondy ML, Hess KR, Myers JN, Hong YK, Yung WK, Steck PA: Differential expression of MMAC/PTEN in glioblastoma multiforme: Relationship to localization and prognosis. Cancer Res 59: 1820-1824, 1999

4. Smith JS, Tachibana I, Passe SM, Huntley BK, Borell TJ, Iturria N, O'Fallon JR, Schaefer PL, Scheithauer BW, James CD, Buckner JC, Jenkins RB: PTEN mutation, EGFR amplification, and outcome in patients with anaplastic astrocytoma and glioblastoma multiforme. J Natl Cancer Inst 93: 1246-1256, 2001

5. Hidalgo M, Rowinsky EK: The rapamycin-sensitive signal transduction pathway as a target for cancer therapy. Oncogene 19: 66806686, 2000

6. Chen J, Fang Y: A novel pathway regulating the mammalian target of rapamycin (mTOR) signaling. Biochem Pharmacol 64: 10711077, 2002

7. Schmelzle T, Hall MN: TOR, a central controller of cell growth. Cell 103: 253-262, 2000

8. Geoerger B, Kerr K, Tang CB, Fung KM, Powell B, Sutton LN, Phillips PC, Janss AJ: Antitumor activity of the rapamycin analog CCI-779 in human primitive neuroectodermal tumor/medulloblastoma models as single agent and in combination chemotherapy. Cancer Res 61: 1527-1532, 2001

9. Chang SM, Kuhn J, Wen P, Greenberg H, Schiff D, Conrad C, Fink K, Robins HI, Cloughesy T, De Angelis L, Razier J, Hess K, Dancey J, Prados MD, North American Brain Tumor Consortium and the National Cancer Institute: Phase I/pharmacokinetic study of CCI-779 in patients with recurrent malignant glioma on enzymeinducing antiepileptic drugs. Invest New Drugs (in press) 22: $427-$ 435, 2004

10. Macdonald DR, Cascino TL, Schold SC, Jr, Cairncross JG: Response criteria for phase II studies of supratentorial malignant glioma. J Clin Oncol 8: 1277-1280, 1990

11. Atkins MB, Hidalgo M, Stadler WM, Logan TF, Dutcher JP, Hudes GR, Park Y, Liou SH, Marshall B, Boni JP, Dukart G, Sherman ML: Randomized phase II study of multiple dose levels of CCI-779, a novel mammalian target of rapamycin kinase inhibitor, in patients with advanced refractory renal cell carcinoma. J Clin Oncol 22: 909-918, 2004

12. Lang FF, Gilbert MR, Puduvalli VK, Weinberg J, Levin VA, Yung WK, Sawaya R, Fuller GN, Conrad CA: Toward better earlyphase brain tumor clinical trials: A reappraisal of current meth- ods and proposals for future strategies. Neuro-oncol 4: 268-277, 2002

13. Gera JF, Mellinghoff IK, Shi Y, Rettig MB, Tran C, Hsu JH, Sawyers CL, Lichtenstein AK: AKT activity determines sensitivity to mammalian target of rapamycin (mTOR) inhibitors by regulating cyclin D1 and c-myc expression. J Biol Chem 279: 2737-2746, 2004

14. Choe G, Horvath S, Cloughesy TF, Crosby K, Seligson D, Palotie A, Inge L, Smith BL, Sawyers CL, Mischel PS: Analysis of the phosphatidylinositol 3'-kinase signaling pathway in glioblastoma patients in vivo. Cancer Res 63: 2742-2746, 2003

15. Klingler-Hoffmann M, Bukczynska P, Tiganis T: Inhibition of phosphatidylinositol 3-kinase signaling negates the growth advantage imparted by a mutant epidermal growth factor receptor on human glioblastoma cells. Int J Cancer 105: 331-339, 2003

16. Schober R, Bilzer T, Waha A, Reifenberger G, Wechsler W, von Deimling A, Wiestler OD, Westphal M, Kemshead JT, Vega F, Delattre JY, Stasiecki-Steinfeld P: The epidermal growth factor receptor in glioblastoma: Genomic amplification, protein expression, and patient survival data in a therapeutic trial. Clin Neuropathol 14: 169-174, 1995

17. Huang S, Houghton PJ: Mechanisms of resistance to rapamycins. Drug Resist Updat 4: 378-391, 2001

18. Hosoi H, Dilling MB, Liu LN, Danks MK, Shikata T, Sekulic A, Abraham RT, Lawrence JC, Jr., Houghton PJ: Studies on the mechanism of resistance to rapamycin in human cancer cells. Mol Pharmacol 54: 815-824, 1998

19. Eshleman JS, Carlson BL, Mladek AC, Kastner BD, Shide KL, Sarkaria JN: Inhibition of the mammalian target of rapamycin sensitizes U87 xenografts to fractionated radiation therapy. Cancer Res 62: 7291-7297, 2002

20. Grunwald V, DeGraffenried L, Russel D, Friedrichs WE, Ray RB, Hidalgo M: Inhibitors of mTOR reverse doxorubicin resistance conferred by PTEN status in prostate cancer cells. Cancer Res 62: 6141-6145, 2002

21. Tanaka M, Koul D, Davies MA, Liebert M, Steck PA, Grossman HB: MMAC1/PTEN inhibits cell growth and induces chemosensitivity to doxorubicin in human bladder cancer cells. Oncogene 19: 54065412,2000

Address for offprints: Susan M. Chang, M.D., Neuro-Oncology Service, University of California, San Francisco, 400 Parnassus Ave, A808, San Francisco, CA 94143. Tel.: 415353 2966; Fax: 415353 2167; E-mail: changs@neurosurg.ucsf.edu 